\title{
Pregnant women's opinions toward prenatal pretest genetic counseling in Japan
}

\author{
Miyuki Nishiyama $\mathbb{1}^{1} \cdot$ Kohei Ogawa $\mathbb{1}^{1} \cdot$ Fuyuki Hasegawa ${ }^{1} \cdot$ Yuki Sekido $^{2} \cdot$ Aiko Sasaki $^{1} \cdot$ Rina Akaishi $^{1}$ • \\ Yoshiyuki Tachibana $^{3} \cdot$ Nagayoshi Umehara $^{1} \cdot$ Seiji Wada ${ }^{1} \cdot$ Nobuaki Ozawa $^{1} \cdot$ Haruhiko Sago $^{1}$
}

Received: 17 October 2020 / Revised: 17 December 2020 / Accepted: 11 January 2021 / Published online: 23 January 2021

(c) The Author(s), under exclusive licence to The Japan Society of Human Genetics 2021

\begin{abstract}
In-person models of genetic counseling (GC) have been the common method in Japan for pregnant women to receive GC. However, recent increases in the number of pregnant women considering undergoing prenatal testing have made it challenging to retain individualized in-person care. To explore pregnant women's opinions toward pretest GC models and the ideal time duration, a self-administered questionnaire survey was conducted for women at their first prenatal visit. A total of 114 valid respondents (93.4\%) were included in the analyses. Of these, $80.7 \%$ of women preferred in-person GC, followed by classroom $(9.6 \%)$, group $(3.5 \%)$, and telegenetic-based GC $(2.6 \%)$. Women with experience in undergoing prenatal testing significantly did not prefer in-person GC $(p=0.05)$. Sixty-two women (54.4\%) preferred a duration of 15-29 $\mathrm{min}$ for pretest GC sessions, followed by $30-59 \mathrm{~min}(28.9 \%)$ and $<15 \mathrm{~min}$ (14.9\%). Women's preference of $\geq 30 \mathrm{~min}$ in length was significantly associated with anhedonia, singleton pregnancies, acquaintance with people with trisomy 21 , and awareness of prenatal testing. Women who were unaware of the need for agreement with the partner for prenatal testing and who did not know the average life expectancy of a trisomy 21 patient significantly preferred $<15$ min in length over other durations. While the majority of women preferred in-person GC for $<30 \mathrm{~min}$, their preferences varied by their background characteristics, experiences, attitudes, and knowledge. These findings will help establish a prenatal GC system offering a choice of GC models in Japan; however, further large-scale studies are needed to confirm these findings.
\end{abstract}

\section{Introduction}

Prenatal testing for aneuploidy is mostly used for advanced maternal age in Japan [1]. Given the increasing trend in the proportion of pregnant women over 35 years old in Japan [2], the introduction of noninvasive prenatal testing (NIPT) for the detection of aneuploidy in a nationwide trial in April 2013 has influenced an increased women's awareness of prenatal testing [3]. The introduction of NIPT has also helped to increase

$\triangle$ Miyuki Nishiyama

nishiyama-my@ncchd.go.jp

1 Center for Maternal-Fetal, Neonatal and Reproductive Medicine, National Center for Child Health and Development, Tokyo, Japan

2 Department of Psychosocial Medicine, National Center for Child Health and Development, Tokyo, Japan

3 Division of Infant and Toddler Mental Health, Department of Psychosocial Medicine, National Center for Child Health and Development, Tokyo, Japan the number of prenatal testing options; however, this situation may have resulted in the phenomenon that pregnant women may feel overwhelmed by the number of choices available [4]. Therefore, prenatal pretest GC has become increasingly important, as GC helps pregnant women sufficiently consider prenatal testing, giving them an appropriate understanding of the test and effectively facilitating their informed choice after adequate consideration [5].

The National Society of Genetic Counselors proposed four service delivery models (SDMs): in-person (referred to as face-to-face traditional), telephone, group, and telegeneticbased (provided remotely using videoconferencing) GC [6]. In-person models of GC have been the common method in Japan. However, this model can be time-intensive and is not practical for serving a large population [7]. Although the implementation rate of prenatal testing in Japan where prenatal screening policies have not been adopted was reported to be $<10 \%$ [8,9], a recent study in Japan suggested that onethird of pregnant women would choose to undergo prenatal testing after being provided information on prenatal testing at their first prenatal visit [10]. 
Given the limited number and involvement of Japanese qualifications for genetic healthcare professionals, such as clinical geneticists and certified genetic counselors, in the clinical practice of prenatal GC [11, 12], the current and emerging demand for prenatal testing may overburden presently available genetic healthcare professionals. Therefore, in Japan, it is necessary to explore appropriate prenatal GC SDMs that do not compromise the quality of care and improve the efficiency and access to GC, with the goal of serving the growing number of pregnant women seeking prenatal testing.

While researchers in other countries have explored alternative GC SDMs in the prenatal setting [13-21], pregnant women's preferences toward models and durations of pretest GC have been poorly studied. In addition, pregnant women's preferences may vary by country and culture. Thus, the present study investigated Japanese pregnant women's opinions toward different models and durations of prenatal pretest GC.

\section{Methods}

\section{Participants}

We conducted a prospective observational study to assess preferences regarding prenatal GC among Japanese pregnant women at the National Center for Child Health and Development (NCCHD) in Tokyo, Japan. As a pilot study to explore pregnant women's preferences concerning prenatal pretest GC models, we set the sample size at over 100 pregnant women in the research plan. Pregnant women attending a general outpatient clinic were recruited at their first prenatal visit before 17 weeks' gestations from June to August 2019.

Participants were asked to complete a self-administered anonymous questionnaire on their preferences toward GC models and prenatal pretest GC duration for chromosomal disorders, their socioeconomic status, attitudes, knowledge and experience with prenatal genetic testing, and knowledge and experience with people affected with trisomy 21 . Women's demographics, their receipt of prenatal testing in this pregnancy, and employment status were retrieved from medical records. In addition to the questionnaire, the participants' maternal mental state was assessed at the women's first prenatal visit using a self-report two-question instrument that asked about depressed mood and anhedonia [22] at the clinical practice in the NCCHD. Participants with missing data were excluded from the data analysis.

All participants provided their written informed consent prior to the questionnaire survey. This study protocol was approved by Institutional Review Board at the NCCHD on May 14, 2019 (project number 2193).

\section{Instrumentation}

A survey instrument on preferences regarding prenatal GC was originally developed with input from maternal fetal medicine physicians, medical geneticists, and genetic counselors at NCCHD. The questionnaire consisted of 28 questions focused on experience and attitudes of prenatal testing (ten questions), preferences toward pretest GC models (five questions), knowledge of congenital disorders including paternal or maternal age effect disorders (five questions), knowledge and experience with people affected with trisomy 21 (four questions), and demographic data, including the age of the father and socioeconomic status (four questions). These items were presented in a multiplechoice format ranging from two to seven potential choices with women allowed to select one of the choices.

Our primary outcome of interest was pregnant women's preferences toward SDMs and the ideal duration of prenatal pretest GC. On the question of GC SDMs, pregnant women were asked, "What model of pretest GC do you prefer?" Possible answers were "in-person GC," "classroom GC," "group GC," "telegenetic-based GC," and "don't know." In the options of "classroom GC" and "group GC," the following description was shown on the questionnaire: "an individual meeting with a genetic counselor one-on-one is available after classroom or group GC sessions."

Regarding the preferences for pretest GC SDMs, we divided the respondents into two groups: in-person GC and other three SDMs (classroom, group, or telegenetic-based), as pretest GC at NCCHD has been delivered as in-person GC models. In addition, we divided the respondents into another two groups (classroom GC or group GC, and inperson or telegenetic-based GC models) to identify factors influencing a preference for non-individualized care at pretest GC.

Regarding the preferences for prenatal pretest GC duration, possible answers were " $<15$," "15-29," "30-59," " $\geq 60 \mathrm{~min}$," and "don't know." We divided these respondents into groups of $<30$ and $\geq 30 \mathrm{~min}$, as pretest $\mathrm{GC}$ at NCCHD has been designed to take $<30 \mathrm{~min}$ in clinical practice. In addition, we divided these respondents into another two groups (those who preferred $<15$ and $\geq 15 \mathrm{~min}$ ) to identify factors influencing a preference for shortduration pretest GC.

\section{Questionnaire}

The first section focused on respondents' experiences and attitudes concerning prenatal testing and contained questions about whether or not they had received a brochure about prenatal testing at their first visit (Q1), when they became aware of prenatal testing (before or after pregnancy) (Q2), their awareness of prenatal testing options (Q3), their 
experience with prenatal testing in a prior pregnancy $(\mathrm{Q} 4)$, opinions concerning the brochures about prenatal testing at the first visit (Q5), opinions concerning the appropriate indications for prenatal testing (Q6), their understanding of the frequency with which prenatal testing is performed among Japanese pregnant women (Q7), experiences discussing prenatal testing with their partners (Q8), whether or not their partner agrees with them about prenatal testing (at the point of the questionnaire) (Q9), and opinions concerning the need for agreement from their partner about prenatal testing (Q10).

The next section focused on opinions concerning pretest GC models and contained questions about the awareness of genetic counseling (Q11), preferences for the duration of pretest GC (Q12), GC models (Q13), people receiving GC together $(\mathrm{Q} 14)$, and their present plan for prenatal testing when answering the questionnaire (Q15).

The next section assessed respondents' knowledge of and experiences with people affected by trisomy 21 and contained questions about their awareness of trisomy 21 (Q21), understanding of the mechanisms involved in trisomy 21 (Q22), knowledge of the average life expectancy of someone with trisomy $21(\mathrm{Q} 23)$, and the growth of trisomy 21 (Q24).

The final section contained questions asking about the age of the respondents' partner (Q25), method of conception $(\mathrm{Q} 26)$, own educational background (Q27), and annual household income (Q28).

\section{Data analyses}

Co-variables, including maternal age, parity (nulliparous, parous), history of spontaneous abortion (yes, no), method of conception (natural conception, assisted reproductive technics, other infertility treatment), fetal number (singleton, multiple gestation), gestational age, receipt of prenatal testing in this pregnancy, and employment status (full-time, parttime, unemployed), were retrieved from the medical records.

We assessed pregnant women's preferences regarding prenatal GC descriptively. The pretest GC session at the NCCHD was conducted using an in-person model and designed to be $<30 \mathrm{~min}$ in duration. To compare maternal demographics among pregnant women who preferred inperson GC, classroom or group GC, and among those who preferred sessions $\geq 30$ and $<15 \mathrm{~min}$ in length, the chi-square test was used. The influence of pregnant women's attitudes, knowledge and experience with prenatal testing and trisomy 21 on their preferences for in-person GC, and a length of $\geq 30$ and $<15$ min was also evaluated using a chi-square test. The participants who responded "don't know" to the two questions about preferences for pretest GC SDMs and time duration were excluded from the statistical analyses for GC SDMs and time duration.
All descriptive and statistical analyses were performed using the statistical software package Stata SE 15 (STATA Corp., College Station, TX, USA). Statistical significance was set at $\leq 0.05$, and all statistical tests were two-tailed.

\section{Results}

Of the 122 pregnant women who consented to participate in our study at the prenatal visit, we excluded 8 with missing data on the following variables: annual household income $(n=4)$, planned prenatal testing at questionnaire $(n=2)$, preference for GC SDMs $(n=1)$, and preference for brochures of prenatal testing $(n=1)$. We therefore conducted our analysis in the remaining 114 women, except for an analysis of the preference for GC SDM based on 110 women (4 were excluded for answering "do not know") and time duration based on 112 women ( 2 were excluded for answering "do not know").

\section{Participants' background characteristics}

The demographic and background characteristics of the participants are shown in Table 1. Sixty-eight women $(59.6 \%)$ were $\geq 35$ years old. Twenty-six $(22.8 \%)$ and 19 $(16.7 \%)$ women answered "yes" to the questions about depressed mood and anhedonia during the past month, respectively. Approximately $25 \%$ of women had a history of spontaneous abortion. Approximately half of pregnancies were achieved by natural conception. Multiple pregnancies accounted for $11.4 \%$ in this study population.

\section{Attitudes and understanding about prenatal testing and people with trisomy 21}

As shown in Table 2, seven (6.1\%) women had experience with undergoing prenatal testing in a prior pregnancy. Participants who knew someone with trisomy 21 or had spoken with people with trisomy 21 accounted for $35.1 \%$. Ultimately, $57.0 \%$ of women did not undergo prenatal testing in this pregnancy. At the questionnaire, 47 women (41.2\%) decided to undergo prenatal testing in this pregnancy, and 33 women $(28.9 \%)$ were undecided about whether or not to undergo prenatal testing. Eightynine women $(78.1 \%)$ indicated the need agreement with the father to undergo prenatal testing. Over $80 \%$ of women had been aware of prenatal testing before this pregnancy. Approximately half of women correctly understood that trisomy 21 is not an inherited disease. Forty-eight women $(42.1 \%)$ correctly understood that the life expectancy of an individual with trisomy 21 was $\geq 40$ years. 
Table 1 Demographic and background characteristics of study participants

\begin{tabular}{|c|c|c|}
\hline \multirow{3}{*}{ Age at questionnaire (years) } & \multicolumn{2}{|l|}{$n=114$} \\
\hline & \multirow[t]{2}{*}{ Number } & \multirow[t]{2}{*}{$\%$ of all } \\
\hline & & \\
\hline & 46 & $40.4 \%$ \\
\hline $35-39$ & 42 & $36.8 \%$ \\
\hline$\geq 40$ & 26 & $22.8 \%$ \\
\hline \multicolumn{3}{|c|}{ Age of husband at questionnaire (years) } \\
\hline$<35$ & 38 & $33.3 \%$ \\
\hline $35-39$ & 40 & $35.1 \%$ \\
\hline$\geq 40$ & 36 & $31.6 \%$ \\
\hline \multicolumn{3}{|l|}{ Age difference among couples } \\
\hline Pregnant women $>$ husbands & 36 & $31.6 \%$ \\
\hline Husbands $>$ pregnant women & 61 & $53.5 \%$ \\
\hline No age difference & 17 & $14.9 \%$ \\
\hline \multicolumn{3}{|l|}{ Education } \\
\hline Middle school & 1 & $0.9 \%$ \\
\hline High school & 8 & $7.0 \%$ \\
\hline Junior college & 24 & $21.1 \%$ \\
\hline University & 74 & $64.9 \%$ \\
\hline Post-graduate & 7 & $6.1 \%$ \\
\hline \multicolumn{3}{|c|}{ Annual household income $(\times 10,000$ yen $)$} \\
\hline$<500$ & 15 & $13.2 \%$ \\
\hline $500-699$ & 22 & $19.3 \%$ \\
\hline $700-999$ & 31 & $27.2 \%$ \\
\hline $1000-1499$ & 27 & $23.7 \%$ \\
\hline$\geq 1500$ & 19 & $16.7 \%$ \\
\hline \multicolumn{3}{|l|}{ Employment } \\
\hline Full-time employment & 71 & $62.3 \%$ \\
\hline Part-time & 12 & $10.5 \%$ \\
\hline Unemployed & 29 & $25.4 \%$ \\
\hline Others & 2 & $1.8 \%$ \\
\hline \multicolumn{3}{|c|}{ Self-reported depressed mood during the past month } \\
\hline Yes & 26 & $22.8 \%$ \\
\hline No & 88 & $77.2 \%$ \\
\hline \multicolumn{3}{|c|}{ Self-reported anhedonia during the past month } \\
\hline Yes & 19 & $16.7 \%$ \\
\hline No & 95 & $83.3 \%$ \\
\hline \multicolumn{3}{|c|}{ Gestational age at questionnaire (weeks) } \\
\hline$<10$ & 46 & $40.4 \%$ \\
\hline$\geq 10$ & 68 & $59.6 \%$ \\
\hline \multicolumn{3}{|l|}{ Parity } \\
\hline Nulliparous & 77 & $67.5 \%$ \\
\hline Parous & 37 & $32.5 \%$ \\
\hline \multicolumn{3}{|l|}{ History of spontaneous abortion } \\
\hline Yes & 30 & $26.3 \%$ \\
\hline No & 84 & $73.7 \%$ \\
\hline \multicolumn{3}{|l|}{ Method of conception } \\
\hline Natural conception & 58 & $50.9 \%$ \\
\hline Assisted reproductive techniques & 38 & $33.3 \%$ \\
\hline Other infertility treatment & 18 & $15.8 \%$ \\
\hline \multicolumn{3}{|l|}{ Fetal number } \\
\hline Singleton & 101 & $88.6 \%$ \\
\hline Multiple & 13 & $11.4 \%$ \\
\hline
\end{tabular}

Table 2 Participants' attitudes and knowledge about prenatal testing and people with trisomy 21

\begin{tabular}{lcr}
\hline & $n=114$ & \\
\cline { 3 - 3 } & Number & $\%$ of all \\
\hline Experience & & \\
Prenatal testing in a prior pregnancy & & \\
$\quad$ Yes & 7 & $6.1 \%$ \\
No & 107 & $93.9 \%$
\end{tabular}

Had someone in their vicinity with T21 or talked with people of T21

$\begin{array}{lrr}\text { Yes } & 40 & 35.1 \% \\ \text { No } & 74 & 64.9 \% \\ \text { Prenatal testing in this pregnancy } & & \\ \text { None } & 65 & 57.0 \% \\ \text { NIPT } & 26 & 22.8 \% \\ \text { MSS } & 22 & 19.3 \% \\ \text { AC/CVS } & 1 & 0.9 \%\end{array}$

\section{Attitudes}

Preference on brochures of prenatal testing at the first visit

$\begin{array}{lll}\text { Wanted to receive } & 77 & 67.5 \%\end{array}$

Neither $\quad 28 \quad 24.6 \%$

Did not want to receive $\quad 1 \quad 0.9 \%$

Don't know $\quad 8 \quad 7.0 \%$

Planned prenatal testing at questionnaire

$\begin{array}{lll}\text { No testing } & 34 & 29.8 \% \\ \text { Undecided } & 33 & 28.9 \% \\ \text { Will have testing } & 47 & 41.2 \%\end{array}$

Needed agreement with the partner for prenatal testing

$\begin{array}{lrr}\text { Yes } & 89 & 78.1 \% \\ \text { Neither } & 9 & 7.9 \% \\ \text { No } & 14 & 12.3 \% \\ \text { Don't know } & 2 & 1.8 \% \\ \text { ant to have GC with husband } & & \\ \text { Yes } & 104 & 91.2 \% \\ \text { No } & 10 & 8.8 \%\end{array}$

Knowledge

Aware of prenatal testing before this pregnancy

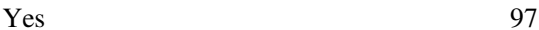

$A C$ amniocentesis, $C V S$ chorionic villus sampling, $G C$ genetic counseling, NIPT noninvasive prenatal testing, MAE maternal age effect, MSS maternal serum screening, $T 21$ trisomy 21 
Table 3 Participants' preferences for prenatal pretest GC

\begin{tabular}{lcc}
\hline & $n=114$ \\
\cline { 3 - 3 } & Number & \\
\hline Preferred GC models all \\
$\quad$ In-person (face-to-face) & 92 & $80.7 \%$ \\
Classroom & 11 & $9.6 \%$ \\
Group & 4 & $3.5 \%$ \\
Telegenetics (provided remotely using & 3 & $2.6 \%$ \\
videoconferencing) & & \\
Don't know & 4 & $3.5 \%$ \\
Preferred duration of pretest GC & & \\
$<15$ min & 17 & $14.9 \%$ \\
15-29 min & 62 & $54.4 \%$ \\
$30-59$ min & 33 & $28.9 \%$ \\
$\geq 60$ min & 0 & $0.0 \%$ \\
Don't know & 2 & $1.8 \%$ \\
\hline$G C$ genetic counseling
\end{tabular}

$G C$ genetic counseling

\section{Preferences regarding prenatal testing and pretest GC}

As shown in Table 3, 92 women (80.7\%) preferred inperson GC, followed by classroom (9.6\%), group (3.5\%), and telegenetic-based GC (2.6\%). Sixty-two women (54.4\%) preferred a duration of $15-29 \mathrm{~min}$ for pretest GC sessions, followed by $30-59 \mathrm{~min}(28.9 \%)$ and $<15 \mathrm{~min}$ (14.9\%). No women preferred a duration $\geq 60 \mathrm{~min}$.

\section{Influence of participant's characteristics on preferences regarding prenatal GC}

The participant characteristics by preference for in-person $\mathrm{GC}$, classroom or group GC, and $\geq 30$ and $<15 \mathrm{~min}$ for duration of pretest GC are shown in Table 4. While 94.7\% of women who reported anhedonia during the past month reported a preference for in-person GC model, the difference was not significant $(p=0.150)$. Among the 35 women who were older than their husbands, 1 (2.9\%) preferred classroom GC, but there was no significant difference ( $p=$ $0.079)$. However, the proportion of women who preferred $\geq 30$-min sessions was significantly higher among women with anhedonia during the past month than those of $<30$ min sessions $(p=0.015)$. No women with multiple pregnancies preferred $\geq 30$-min sessions, and women with singleton pregnancies significantly preferred $\geq 30$-min sessions $(p=0.018)$. Women $<35$ years old and without depressed mood were more likely to prefer $<15$-min sessions over other durations, but there was no significant difference ( $p=$ 0.071 and $p=0.077$, respectively). No other demographic variables were significantly associated with the preference for in-person GC, classroom or group GC, or a duration $\geq 30$ or $<15 \mathrm{~min}$ for pretest GC.

Influence of participant's experience, attitudes, and knowledge on preferences regarding prenatal GC

The influence of participant's experience, attitudes, and knowledge on their preferences for in-person GC, classroom or group GC, or session durations of $\geq 30$ or $<15 \mathrm{~min}$ for pretest GC is shown in Table 5. Women who underwent prenatal testing in a prior pregnancy did not prefer in-person GC significantly $(p=0.05)$. In-person GC was preferred by $31 / 33(93.9 \%)$ and $25 / 32(78.1 \%)$ of those who were undecided and who had decided to undergo prenatal testing at the time of the questionnaire, respectively $(p=0.157)$. Among the 24 women who did not need agreement with the partner to undergo prenatal testing, 22 (91.7\%) preferred inperson GC. Thus, among such women, none of them preferred classroom or group GC, while those who felt that they needed agreement with their partner to undergo testing significantly preferred classroom or group GC to other options $(p=0.028)$. No other variables were significantly associated with the preference for in-person GC or classroom or group GC.

With regard to the pretest GC duration, women who were acquainted with someone with trisomy 21 or had talked to people with trisomy 21 as well as those who were aware of prenatal testing before this pregnancy significantly preferred $\geq 30$-min sessions for pretest GC $(p=0.017$ and $p=0.037$, respectively). Over $20 \%$ of women who did not need agreement with the partner for prenatal testing and those who were unaware of the average life expectancy of a trisomy 21 individual significantly preferred $<15$-min sessions for pretest GC $(p=0.043$ and $p=0.027$, respectively). Among women who were unaware of GC and those who lacked an understanding of the mechanism of trisomy 21 , the frequency of preference for $<15$-min sessions for pretest GC was $\sim 20 \%$, although the difference was not significant ( $p=0.056$ and $p=0.054$, respectively).

\section{Discussion}

In this study population, $80.7 \%$ of pregnant women preferred traditional in-person GC for pretest GC. Pregnant women who had undergone prenatal testing in a prior pregnancy did not prefer in-person GC significantly. Pregnant women with singleton pregnancy, anhedonia during the past month, recognition of prenatal testing, and personal experience with people with trisomy 21 significantly preferred $\geq 30$-min sessions for pretest GC to other durations. Women who did not need agreement with the partner for prenatal testing and were unaware of the average life 
Table 4 Demographic and background characteristics of study participants with a preference for pretest GC model and duration

\begin{tabular}{|c|c|c|c|c|c|c|c|c|c|c|}
\hline & \multicolumn{5}{|c|}{ Preferences toward pretest GC model } & \multicolumn{5}{|c|}{ Preferences toward pretest GC duration (minutes in length) } \\
\hline & \multirow{2}{*}{$\begin{array}{l}n=110^{\mathrm{a}} \\
\text { Number }\end{array}$} & \multicolumn{2}{|l|}{$\begin{array}{l}\text { In-person GC } \\
(n=92)\end{array}$} & \multicolumn{2}{|c|}{$\begin{array}{l}\text { Classroom or group } \\
\text { GC }(n=15)\end{array}$} & \multirow{2}{*}{$\begin{array}{l}n=112^{b} \\
\text { Number }\end{array}$} & \multicolumn{2}{|l|}{$\geq 30^{c}(n=33)$} & \multicolumn{2}{|l|}{$<15(n=17)$} \\
\hline & & Number $(\%)$ & $p$ value & Number $(\%)$ & $p$ value & & Number $(\%)$ & $p$ value & Number $(\%)$ & $p$ value \\
\hline $\begin{array}{l}\text { Age at questionnaire } \\
\text { (years) }\end{array}$ & & & 0.611 & & 0.461 & & & 0.120 & & 0.071 \\
\hline$<35$ & 49 & $40 / 49(81.6)$ & & $8 / 49(16.3)$ & & 50 & $11 / 50(22.0)$ & & $11 / 50(22.0)$ & \\
\hline$\geq 35$ & 61 & $52 / 61(85.2)$ & & $7 / 61(11.5)$ & & 62 & $22 / 62(35.5)$ & & $6 / 62(9.7)$ & \\
\hline $\begin{array}{l}\text { Age of husband at } \\
\text { questionnaire (years) }\end{array}$ & & & 0.906 & & 0.915 & & & 0.402 & & 0.182 \\
\hline$<35$ & 38 & $32 / 38(84.2)$ & & $5 / 38(13.2)$ & & 37 & $9 / 37(24.3)$ & & $8 / 37(21.6)$ & \\
\hline$\geq 35$ & 72 & $60 / 72(83.3)$ & & $10 / 72(13.9)$ & & 75 & $24 / 75(32.0)$ & & $9 / 75(12.0)$ & \\
\hline $\begin{array}{l}\text { Age difference among } \\
\text { couples }\end{array}$ & & & 0.306 & & 0.079 & & & 0.515 & & 0.898 \\
\hline $\begin{array}{l}\text { Pregnant women > } \\
\text { husbands }\end{array}$ & 35 & 32/35 (91.4) & & $1 / 35(2.9)$ & & 36 & $10 / 36(27.8)$ & & 6/36 (16.7) & \\
\hline $\begin{array}{l}\text { Husbands > } \\
\text { pregnant women }\end{array}$ & 58 & 46/58 (79.3) & & 11/58 (19.0) & & 59 & $16 / 59(27.1)$ & & $9 / 59(15.3)$ & \\
\hline No age difference & 17 & $14 / 17(82.4)$ & & 3/17 (17.7) & & 17 & 7/17 (41.2) & & 2/17 (11.8) & \\
\hline Education. & & & 0.539 & & 0.888 & & & 0.844 & & 0.617 \\
\hline $\begin{array}{l}\text { University or higher } \\
\text { level degree }\end{array}$ & 79 & $65 / 79(82.3)$ & & $11 / 79(13.9)$ & & 80 & $24 / 80(30.0)$ & & $13 / 80(16.3)$ & \\
\hline Others & 31 & 27/31 (87.1) & & 4/31 (12.9) & & 32 & $9 / 32(28.1)$ & & $4 / 32(12.5)$ & \\
\hline $\begin{array}{l}\text { Annual household income } \\
(\times 10,000 \text { yen })\end{array}$ & & & 0.167 & & 0.292 & & & 0.462 & & 0.089 \\
\hline$<1000$ & 65 & $57 / 65(87.7)$ & & 7/65 (10.8) & & 67 & 18/67 (26.9) & & 7/67 (10.5) & \\
\hline$\geq 1000$ & 45 & $35 / 45$ (77.8) & & $8 / 45(17.8)$ & & 45 & $15 / 45(33.3)$ & & $10 / 45(22.2)$ & \\
\hline Employment & & & 0.320 & & 0.677 & & & 0.477 & & 0.408 \\
\hline Full-time employment & 68 & $55 / 68(80.9)$ & & 5/42 (11.9) & & 69 & $22 / 69$ (31.9) & & $12 / 69(17.4)$ & \\
\hline Others & 42 & $37 / 42(88.1)$ & & $10 / 68(14.7)$ & & 43 & $11 / 43(25.6)$ & & $5 / 43$ (11.6) & \\
\hline $\begin{array}{l}\text { Self-reported depressed } \\
\text { mood during the } \\
\text { past month }\end{array}$ & & & 0.502 & & 0.786 & & & 0.190 & & 0.077 \\
\hline Yes & 25 & $22 / 25(88.0)$ & & $3 / 25(12.0)$ & & 25 & $10 / 25(40.0)$ & & $1 / 25(4.0)$ & \\
\hline No & 85 & $70 / 85$ (82.4) & & $12 / 85(14.1)$ & & 87 & 23/87 (26.4) & & 16/87 (18.4) & \\
\hline $\begin{array}{l}\text { Self-reported anhedonia } \\
\text { during the past month }\end{array}$ & & & 0.150 & & 0.242 & & & 0.015 & & 0.186 \\
\hline Yes & 19 & $18 / 19(94.7)$ & & $1 / 19(5.3)$ & & 19 & $10 / 19(52.6)$ & & $1 / 19(5.3)$ & \\
\hline No & 91 & 74/91 (81.3) & & 14/91 (15.4) & & 93 & 23/93 (24.7) & & 16/93 (17.2) & \\
\hline $\begin{array}{l}\text { Gestational age at } \\
\text { questionnaire (weeks) }\end{array}$ & & & 0.739 & & 0.626 & & & 0.513 & & 0.599 \\
\hline$<10$ & 45 & $37 / 45(82.2)$ & & $7 / 45$ (15.5) & & 46 & $12 / 46(26.1)$ & & 6/46 (13.0) & \\
\hline$\geq 10$ & 65 & $55 / 65$ (84.6) & & $8 / 65(12.3)$ & & 66 & 21/66 (31.8) & & $11 / 66(16.7)$ & \\
\hline Parity & & & 0.542 & & 0.957 & & & 0.691 & & 0.730 \\
\hline Nulliparous & 74 & $63 / 74(85.1)$ & & 10/74 (13.5) & & 75 & 23/75 (30.7) & & $12 / 75(16.0)$ & \\
\hline Parous & 36 & 29/36 (80.6) & & $5 / 36(13.9)$ & & 37 & 10/37 (27.0) & & $5 / 37(13.5)$ & \\
\hline $\begin{array}{l}\text { History of spontaneous } \\
\text { abortion }\end{array}$ & & & 0.074 & & 0.571 & & & 0.139 & & 0.742 \\
\hline Yes & 30 & $22 / 30(73.3)$ & & $5 / 30(16.7)$ & & 30 & $12 / 30(40.0)$ & & 4/30 (13.3) & \\
\hline No & 80 & $70 / 80(87.5)$ & & $10 / 80(12.5)$ & & 82 & $21 / 82(25.6)$ & & $13 / 82$ (15.9) & \\
\hline
\end{tabular}


Table 4 (continued)

\begin{tabular}{|c|c|c|c|c|c|c|c|c|c|c|}
\hline & \multicolumn{5}{|c|}{ Preferences toward pretest GC model } & \multicolumn{5}{|c|}{ Preferences toward pretest GC duration (minutes in length) } \\
\hline & \multirow{2}{*}{$\begin{array}{l}n=110^{\mathrm{a}} \\
\text { Number }\end{array}$} & \multicolumn{2}{|l|}{$\begin{array}{l}\text { In-person GC } \\
(n=92)\end{array}$} & \multicolumn{2}{|c|}{$\begin{array}{l}\text { Classroom or group } \\
\mathrm{GC}(n=15)\end{array}$} & \multirow{2}{*}{$\begin{array}{l}n=112^{\mathrm{b}} \\
\text { Number }\end{array}$} & \multicolumn{2}{|l|}{$\geq 30^{c}(n=33)$} & \multicolumn{2}{|l|}{$<15(n=17)$} \\
\hline & & Number $(\%)$ & $p$ value & Number $(\%)$ & $p$ value & & Number $(\%)$ & $p$ value & Number $(\%)$ & $p$ value \\
\hline Method of conception & & & 0.666 & & 0.449 & & & 0.457 & & 0.216 \\
\hline Natural conception & 56 & $46 / 56(82.1)$ & & $9 / 56(16.1)$ & & 57 & $15 / 57(26.3)$ & & $11 / 57(19.3)$ & \\
\hline $\begin{array}{l}\text { Pregnancy after } \\
\text { infertility treatment }\end{array}$ & 54 & $46 / 54(85.2)$ & & $6 / 54(11.1)$ & & 55 & $18 / 55(32.7)$ & & $6 / 55(10.9)$ & \\
\hline Fetal number & & & 0.492 & & 0.643 & & & & & \\
\hline Singleton & 99 & $82 / 99(82.8)$ & & $14 / 99(14.1)$ & & 100 & $33 / 100(33.0)$ & 0.018 & $15 / 100(15.0)$ & 0.879 \\
\hline Multiple & 11 & $10 / 11(90.9)$ & & $1 / 11(9.1)$ & & 12 & $0 / 12(0.0)$ & & $2 / 12(16.7)$ & \\
\hline
\end{tabular}

$G C$ genetic counseling

aFour participants who answered "don't know" to the questions about preference for GC models were excluded from this analysis

bTwo participants who answered "don't know" to the questions about preference for duration of pretest GC time were excluded from this analysis

'Includes participants who preferred $30-59$ min only, as no participants preferred $\geq 60 \mathrm{~min}$

expectancy of trisomy 21 individuals significantly preferred $<15$-min sessions to other durations. While the majority of women preferred in-person GC with $\geq 30$-min sessions for pretest GC, their preferences varied by background characteristics, experience, attitudes, and knowledge. To our knowledge, this is the first study on pregnant women's preferences concerning different models and durations of prenatal pretest GC.

\section{A strong preference for in-person GC}

In our study population, the proportion of pregnant women who preferred traditional in-person GC was over $80 \%$, which was higher than that in previously published studies from Latin and Italian populations, which reported that roughly half of pregnant women indicated a preference for in-person GC [17, 23]. Such differences may reflect cultural and personal preferences in the study populations. One-third of pregnant Latina women stated that advantages of group GC included the value of hearing the perspectives of other individuals in a similar situation to their own and the opportunity to learn from others [23]. In this study, $3.5 \%$ and $9.6 \%$ of women stated preferences for group GC and classroom GC, respectively. One possible explanation for this difference is that Japanese pregnant women may be uncomfortable sharing GC information in front of others and wish for privacy and the focused attention of a genetic counselor, which they can receive in individual sessions. In this study, a history of having undergone prenatal testing in a prior pregnancy was the only significant factor associated with non-preference for in-person GC. This finding suggests that these women thought that they already understood the information of prenatal testing and the process of GC.

\section{Alternative GC models for the Japanese population}

While it is important to improve pregnant women's access to prenatal GC, it is paramount that their reported outcomes be considered when implementing alternative GC SDMs. Previous studies have demonstrated the utility of providing digital information on prenatal testing before in-person GC, which was confirmed to help improve patients' knowledge $[13,21]$, shorten the time required [21], and reduce decision conflict $[13,16,20]$. Considering our finding that Japanese women tend to prefer in-person GC, such an approach would likely be acceptable in a Japanese population. Although telegenetic-based GC, described as web-based or videoconferencing $\mathrm{GC}$, also has advantages of interactive visual communication and satisfying pregnant women's preference for individual counseling [14], this approach was preferred by the smallest proportion of pregnant women (2.6\%) in this study population. Telegenic GC was less acceptable to pregnant women in Japan. To understand why in-person (face-to face) GC was preferred among Japanese women, further studies are warranted.

\section{Influence of women's experiential knowledge of trisomy 21}

While pregnant women's understanding of the mechanism and average life expectancy of trisomy 21 were not significantly associated with their preferences for prenatal pretest GC models and durations, women who had an acquaintance with trisomy 21 or had talked with people with trisomy 21 significantly preferred $\geq 30$-min sessions for pretest GC to other durations. This finding suggests that their experiential knowledge acquired from personal experience with trisomy 21 may play a role in prenatal 


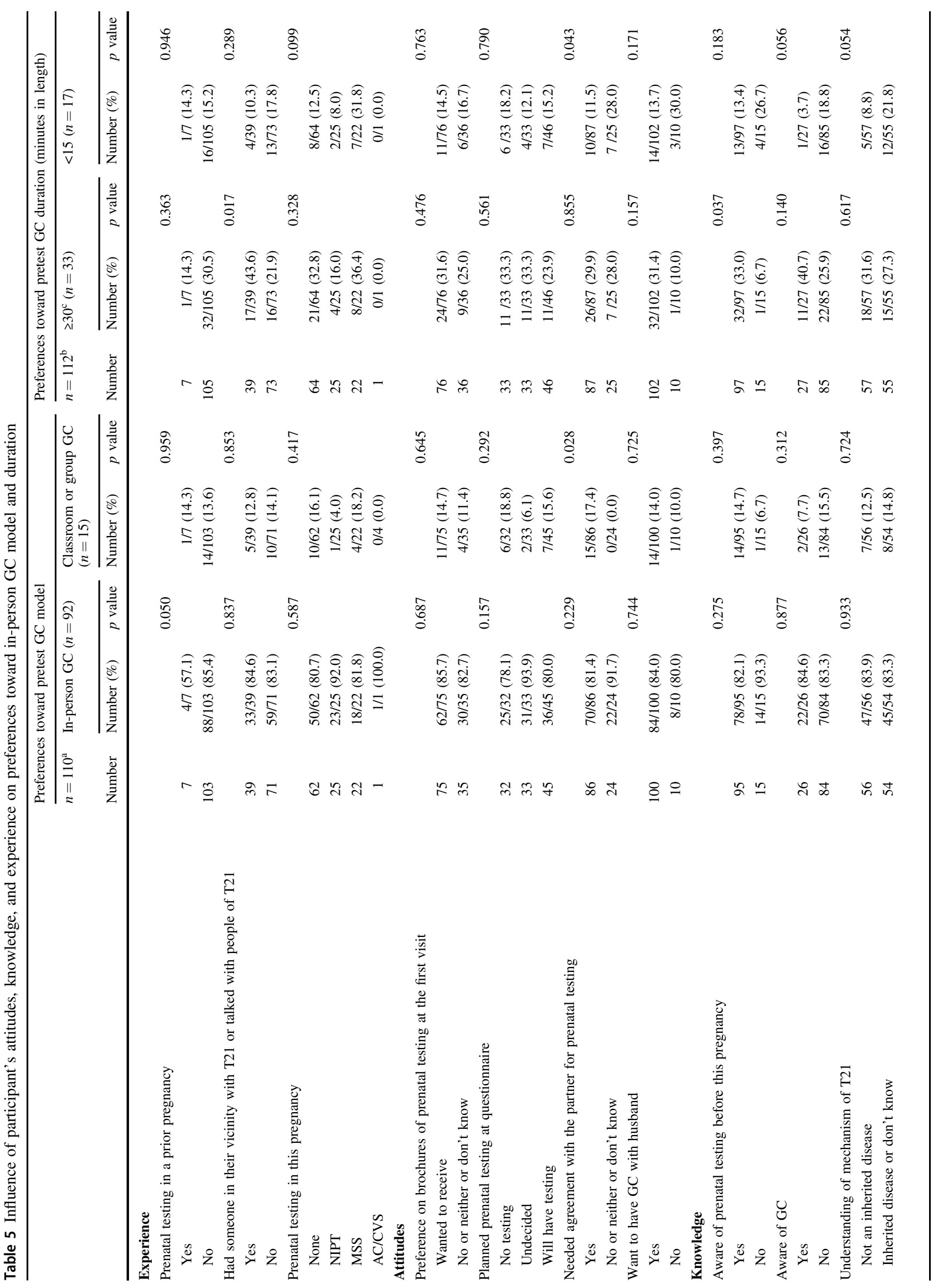




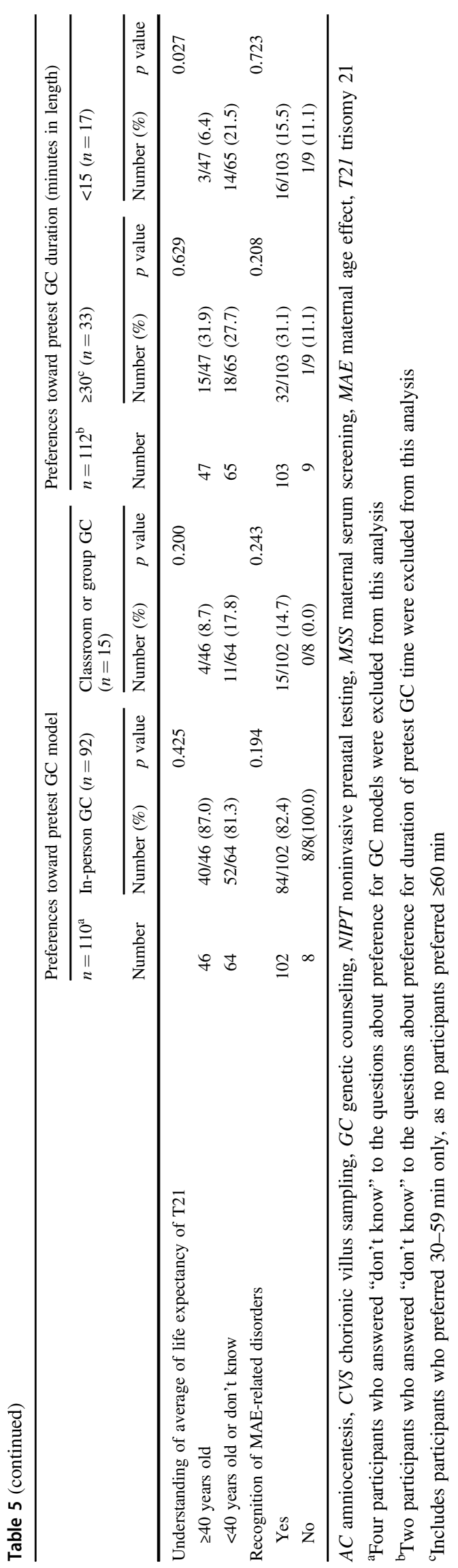

decision-making, as shown in a previous report among Canadian women [24]. For instance, women declining prenatal testing tended to know someone with trisomy 21 [25]. Those findings suggest that our study participants with experiential knowledge of trisomy 21 need time at pretest GC to carefully consider the value of prenatal testing and whether or not to undergo prenatal testing based on their experiential knowledge of trisomy 21 .

\section{Maternal mental stress as a predictor of an appropriate GC method}

In this study, the prevalence of a depressive mental status, such as depression or anhedonia, was over $20 \%$, which was higher than the previously reported prevalence of depression at the first trimester, where $11 \%$ of pregnant women had been diagnosed with depression according to a diagnostic interview [26]. This difference may be due to the fact that the prevalence of depression among this study population relied solely on a self-reported two-question instrument to identify depression. Some patients who test positive for depression with such an instrument were reportedly not found to have depression in a diagnostic interview [22]. The prevalence of a depressive mental status using a self-report two-question instrument may therefore be overestimated. Approximately $95 \%$ of pregnant women with anhedonia during the past month preferred in-person GC, with a significant preference for a longer duration of prenatal GC. This finding suggests that anhedonia during the past month is a predictor of women's preference for the prenatal GC method. Although there have been no studies assessing the association between maternal mental stress and women's preferences for prenatal GC method, difficulty making decisions is a core symptom of depressive disorders. Our findings also suggest that depressed women require more time to decide whether or not to undergo prenatal testing. At in-person $\mathrm{GC}$, there is more time for an exploration of women's values, concerns and emotions, so in-person GC allows for more personalized psychosocial support.

\section{Influence of women's awareness of prenatal testing}

Among women who had been aware of prenatal testing before this pregnancy, the proportion who preferred $\geq 30$ min sessions for prenatal pretest GC was significantly higher than those of $>30 \mathrm{~min}$. This significant association may be due to the knowledge acquired before they become pregnant leading them to be more aware of the importance of pretest GC, although this study did not assess the level of their understanding. No studies have examined the relationship between pregnant women's awareness of prenatal testing and their preference for prenatal GC methods. Our findings suggest that providing sufficient information about 
prenatal testing to women before pregnancy might influence the decision-making process concerning prenatal testing once they become pregnant.

\section{Pregnant women who preferred short-duration pretest GC}

Approximately $15 \%$ of women preferred $<15$-min sessions for pretest GC. Factors that were significantly associated with a preference for $<15$-min sessions were not knowing whether or not agreement with the partner was necessary for prenatal testing and a misunderstanding of the average life expectancy of trisomy 21 individuals. These findings suggest that women without the partner's agreement and lacking basic education on trisomy 21 might more easily agree to prenatal testing than others. If prenatal testing is conducted in these pregnant women, the test results might create anxiety and conflict concerning the decision. While the present study did not address these issues, the involvement of the partner in the prenatal testing decision-making process and understanding of trisomy 21 might affect pregnant women's awareness of the importance of pretest GC.

\section{Limitations of the study}

Several limitations associated with the present study warrant mention. First, our study was conducted in a population of a fairly high socioeconomic status: over $70 \%$ of the pregnant women in the present study were university graduates or better, and $\sim 70 \%$ of the participants had an annual household income of $\geq 7$ million yen. In addition, our study included a high prevalence of subjects with an advanced maternal age, pregnancies achieved by infertility treatment, and multiple pregnancies. Thus, to confirm our findings, further replicative studies on other population are encouraged. Second, in the absence of a validated instrument specific to our research questions, our study used one developed originally for this study. However, the current study focused on pregnant women's preferences toward the models and duration of pretest GC, which will enable us to explore Japanese pregnant women's preferences regarding prenatal GC and establish valuable pretest GC SDMs in this country. At present, various GC methods are being considered due to the ongoing COVID-19 outbreak. This study was conducted prior to the COVID-19 outbreak.

\section{Conclusion}

We reported that over $80 \%$ of Japanese pregnant women preferred traditional in-person GC for pretest GC. While most women preferred in-person GC for $<30$ min in length for prenatal pretest GC SDMs, women's preferences may vary by their background characteristics, experience, and knowledge. These findings will help establish a prenatal GC system offering a choice of GC SDMs in Japan, along with further large-scale studies of pregnant women's preferences and the reported outcomes of prenatal GC SDMs.

Acknowledgements We would like to thank the pregnant women who participated in this study. The study received support from the Grant of National Center for Child Health and Development 2019C-7 of Japan.

\section{Compliance with ethical standards}

Conflict of interest The authors declare that they have no conflict of interest.

Publisher's note Springer Nature remains neutral with regard to jurisdictional claims in published maps and institutional affiliations.

\section{References}

1. Nishiyama M, Yan J, Yotsumoto J, Sawai H, Sekizawa A, Kamei Y, et al. Chromosome abnormalities diagnosed in utero: a Japanese study of 28983 amniotic fluid specimens collected before 22 weeks gestations. J Hum Genet. 2015;60:133-7.

2. Vital Statistics of Japan, Ministry of Health Labour and Welfare. Live births born in wedlock by single years of age of father and mother and live birth order: Japan. 2020. https://wwwe-sta tgojp/en.

3. Sago H, Sekizawa A, Japan NIPT consortium. Nationwide demonstration project of next-generation sequencing of cell-free DNA in maternal plasma in Japan: 1-year experience. Prenat Diagn. 2015;35:331-6.

4. Wilson KL, Czerwinski JL, Hoskovec JM, Noblin SJ, Sullivan CM, Harbison A, et al. NSGC practice guideline: prenatal screening and diagnostic testing options for chromosome aneuploidy. J Genet Couns. 2013;22:4-15.

5. Farrelly E, Cho MK, Erby L, Roter D, Stenzel A, Ormond K. Genetic counseling for prenatal testing: where is the discussion about disability? J Genet Couns. 2012;21:814-24.

6. Cohen SA, Gustafson SL, Marvin ML, Riley BD, Uhlmann WR, Liebers SB, et al. Report from the National Society of Genetic Counselors service delivery model task force: a proposal to define models, components, and modes of referral. J Genet Couns. 2012; 21:645-51.

7. Cohen SA, Marvin ML, Riley BD, Vig HS, Rousseau JA, Gustafson SL. Identification of genetic counseling service delivery models in practice: a report from the NSGC Service Delivery Model Task Force. J Genet Couns. 2013;22:411-21.

8. Sasaki A, Sawai H, Masuzaki H, Hirahara F, Sago H. Low prevalence of genetic prenatal diagnosis in Japan. Prenat Diagn. 2011;31:1007-9.

9. Sasaki A, Yoshihashi H, Yamada S, Miyake H, Suzumori N, Takada F, et al. Current status of prenatal diagnosis in Japan 19982016. Nihon Shuusanki Shinseiji Igakkai Zasshi. 2018;54:101-7.

10. Shibata M, Akaishi R, Sasaki A, Ogawa K, Nishiyama M, Wada $S$, et al. Pregnant women's preferences for prenatal genetic testing: a single-center study in Japan. J Obstet Gynaecol Res. 2020;46: 1972-6.

11. Nishiyama M, Sawai H, Kosugi S. The current state of genetic counseling before and after amniocentesis for fetal karyotyping in Japan: a survey of obstetric hospital clients of a prenatal testing laboratory. J Genet Couns. 2013;22:795-804. 
12. Miyake H, Yamada S, Fujii Y, Sawai H, Arimori N, Yamanouchi Y, et al. Nationwide survey for current clinical status of amniocentesis and maternal serum marker test in Japan. J Hum Genet. 2016;61:879-84.

13. Hunter AG, Cappelli M, Humphreys L, Allanson JE, Chiu TT, Peeters $\mathrm{C}$, et al. A randomized trial comparing alternative approaches to prenatal diagnosis counseling in advanced maternal age patients. Clin Genet. 2005;67:303-13.

14. Abrams DJ, Geier MR. A comparison of patient satisfaction with telehealth and on-site consultations: a pilot study for prenatal genetic counseling. J Genet Couns. 2006;15:199-205.

15. Knutzen DM, Stoll KA, McClellan MW, Deering SH, Foglia LM. Improving knowledge about prenatal screening options: can group education make a difference? J Matern Fetal Neonatal Med. 2013;26:1799-803.

16. Kuppermann M, Pena S, Bishop JT, Nakagawa S, Gregorich SE, Sit A, et al. Effect of enhanced information, values clarification, and removal of financial barriers on use of prenatal genetic testing: a randomized clinical trial. JAMA. 2014;312:1210-7.

17. Godino L, Pompilii E, D’Anna F, Morselli-Labate AM, Nardi E, Seri M, et al. Attitudes of women of advanced maternal age undergoing invasive prenatal diagnosis and the impact of genetic counselling. Eur J Hum Genet. 2016;24:331-7.

18. Cloutier M, Gallagher L, Goldsmith C, Akiki S, Barrowman N, Morrison S. Group genetic counseling: an alternate service delivery model in a high risk prenatal screening population. Prenat Diagn. 2017;37:1112-9.
19. Gammon BL, Otto L, Wick M, Borowski K, Allyse M. Implementing group prenatal counseling for expanded noninvasive screening options. J Genet Couns. 2018;27:894-901.

20. Carlson LM, Harris S, Hardisty EE, Hocutt G, Vargo D, Campbell E, et al. Use of a novel computerized decision aid for aneuploidy screening: a randomized controlled trial. Genet Med. 2019;21: 923-9.

21. de Leeuw RA, van der Horst SFB, de Soet AM, van Hensbergen JP, Bakker P, Westerman M, et al. Digital vs face-to-face information provision in patient counselling for prenatal screening: a noninferiority randomized controlled trial. Prenat Diagn. 2019;39: 456-63.

22. Whooley MA, Avins AL, Miranda J, Browner WS. Case-finding instruments for depression. Two questions are as good as many. J Gen Intern Med. 1997;12:439-45.

23. Thompson S, Noblin SJ, Lemons J, Peterson SK, Carreno C, Harbison A. Perceptions of Latinas on the traditional prenatal genetic counseling model. J Genet Couns. 2015;24:675-82.

24. Etchegary H, Potter B, Howley H, Cappelli M, Coyle D, Graham I, et al. The influence of experiential knowledge on prenatal screening and testing decisions. Genet Test. 2008;12:115-24.

25. Ternby E, Axelsson O, Anneren G, Lindgren P, Ingvoldstad C. Why do pregnant women accept or decline prenatal diagnosis for Down syndrome? J Community Genet. 2016;7:237-42.

26. Gavin NI, Gaynes BN, Lohr KN, Meltzer-Brody S, Gartlehner G, Swinson T. Perinatal depression: a systematic review of prevalence and incidence. Obstet Gynecol. 2005;106:1071-83. 